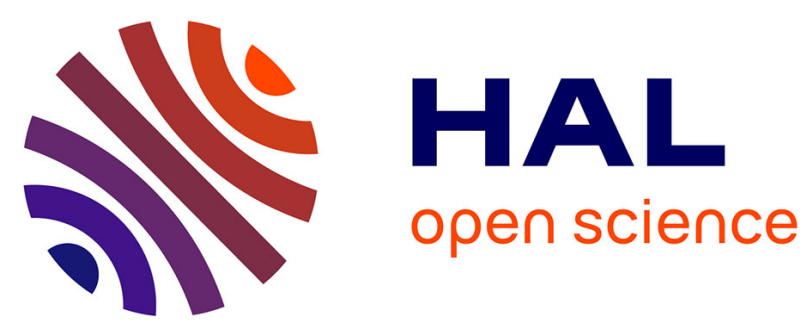

\title{
Proposal of an Activity-Based Adaptive Process Model for Innovative Design
}

Qiang Zhang, Ioana Deniaud, Claude Baron, Emmanuel Caillaud

\section{To cite this version:}

Qiang Zhang, Ioana Deniaud, Claude Baron, Emmanuel Caillaud. Proposal of an Activity-Based Adaptive Process Model for Innovative Design. ASME 2013 International Design Engineering Technical Conferences and Computers and Information in Engineering Conference, Aug 2013, Portland, United States. 10p., 10.1115/DETC2013-12581 . hal-01771710

\section{HAL Id: hal-01771710 \\ https://hal.univ-lorraine.fr/hal-01771710}

Submitted on 7 Mar 2019

HAL is a multi-disciplinary open access archive for the deposit and dissemination of scientific research documents, whether they are published or not. The documents may come from teaching and research institutions in France or abroad, or from public or private research centers.
L'archive ouverte pluridisciplinaire HAL, est destinée au dépôt et à la diffusion de documents scientifiques de niveau recherche, publiés ou non, émanant des établissements d'enseignement et de recherche français ou étrangers, des laboratoires publics ou privés. 
August 4-7, 2013, Portland, Oregon, USA

\section{DETC2013-12581}

\section{PROPOSAL OF AN ACTIVITY-BASED ADAPTIVE PROCESS MODEL FOR INNOVATIVE DESIGN}

\author{
Qiang Zhang \\ LGECO/INSA de Strasbourg \\ Strasbourg, France, 67084 \\ qiang.zhang@insa-strasbourg.fr \\ Claude Baron ${ }^{1,2}$ \\ ${ }^{1}$ CNRS, LAAS ${ }^{2}$ Université de Toulouse, INSA \\ Toulouse, France, 31077 \\ claude.baron@insa-toulouse.fr
}

\author{
loana Deniaud \\ BETA/ Université de Strasbourg \\ Strasbourg, France, 67085 \\ deniaud@unistra.fr \\ Emmanuel Caillaud \\ ICUBE/ Université de Strasbourg \\ Strasbourg, France, 67084 \\ emmanuel.caillaud@unistra.fr
}

\begin{abstract}
In this paper, we introduced an activity-based adaptive process model that views innovative design as a complex adaptive system. Instead of predefining the process architecture, we constructed the model framework by adaptively selecting the design activity by the activity value. We defined the activity value as the complexity reduction associated with the possibility of satisfying the design targets and design stages. Moreover, this paper contributes an expert evaluation methodology to evaluate the activity value in order to balance innovation and control. Finally, we applied the model to an industrial case and analyzed the simulation results.
\end{abstract}

Keywords: innovative design, adaptive model, complexity, activity value

\section{INTRODUCTION}

An increased focus on product design can obviously be observed to varying degrees in industry [1]. Product design is increasingly recognized by managers as a strategy tool (to be) responsible for the success of firms. However, new challenges, including technical advances, intensive customer needs, increasing diversification of the market and increasing world competition may threaten the strategic position of companies. Thus, in order to get sustainable sources of competitive advantage, companies that develop innovative products have realized the importance of improving the efficiency and predictability of innovative design processes. Since process improvement first requires process understanding, gaining a comprehensive understanding of the processes of innovative design through a process model is of major interest to both individuals and organizations.
When dealing with innovative projects, the main point is to find the proper balance between a firmly guided process and a completely free process, as opposed to routine development, which favors innovation but which is difficult to control in a company.

The purpose of this paper is to propose a process model, based on a flexible framework, in order to guide innovation in design. Considering a process as "a set of interrelated or interacting activities which transform inputs into outputs"[2], to address this purpose, we built this model using an activitybased representation. Most existing process models have two assumptions: first, that the design activities are known a priori [3]; secondly, that the expected goal can be achieved by these known design activities. However, innovative design, as opposed to routine design and variant design, tries to break away from existing rules and to generate new rules. During this process, it applies creative ideas or it creatively applies existing ideas to create a product, process or service for a customer and market [4]. In practice, it is impossible to recognize all relevant influence factors and their functional relationships, even the emerging unexpected events and new information during operation. Therefore, innovative design involves foreseen uncertainty and unforeseen uncertainty, chaos, even a blend of types.

As for unforeseen uncertainty and chaos, it is impossible to develop a complete contingency model, and the model should evolve as the project proceeds. Therefore, in order to facilitate 'real-time orientations' of this process, at each agreed decision point of the process a set of possible activities is considered depending on the current design situation. We offer the designer the possibility to choose among them by assigning value to each activity. This value is calculated from expert assessments 
based on the complexity of the process and also of the product being designed. So this model progressively builds the process architecture by adaptively selecting the design activity. The activity value, as the selecting criterion to balance innovation and control, is determined by expert evaluations based on the current process and product complexity. More precisely, we use the function of the information that reduces complexity and the corresponding design metrics in the light of the current design situation. This process model thus becomes adaptive and promotes innovative design.

Section 2 defines the framework for this adaptive model; it discusses the characteristics of innovative design, and considers innovative design as a complex adaptive system. Section 3 indicates how the model is progressively built using expert evaluations; it also analyzes the evaluation basis, and proposes a methodology to evaluate the activity value. Section 4 describes the simulations carried out on the model in an industrial case and discusses the results. Section 5 sums up our contributions and submits some possible further perspectives.

\section{ADAPTIVE MODEL FRAMEWORK}

\subsection{Model Framework}

In this paper, we consider the process of innovative design as a complex adaptive system (CAS). A CAS is a complicated system composed of independent but connected agents with the adaptive ability to self-organize and cause the emergence of new system configurations and corresponding levels of order or disorder[5]. Adaptability, as the ability of a CAS to be changed to fit varied circumstances, is a value variable of system performance [6]. The following phenomena of the CAS, nonlinearity, self-organization and system evolution, are the basis of adaptability in a CAS.

Non-linearity. Because the behavior of a CAS stems from the interactions between many coupled agents, the CAS behaves in a non-linear fashion according to a power law. The process of innovative design is composed of feedback loops and iteration due to a variety of uncertainties from incomplete or new information. It results in non-linear behavior of innovative design. In other words, there is no direct and clear correlation between the size of the cause and the size of the corresponding result.

Self-organization. Individual agents adopt simple behaviors to self-organize without the intervention of a central controller. After the interactions between a large number of agents involve positive feedback loops, the collective behavior of these agents eventually results in the emergence of new system configurations. In practice, while facing design problems with innovative design, each design activity observes and interprets the emergent information, and then responds in accordance to the current state. Through many (times of) exploratory actions and experiments, stable and new process characteristics emerge. Therefore, the "self-organization" phenomenon also exists in the process of innovative design.

System evolution. Every aspect of the CAS-Agent, such as schemata (the strength and type of connections between agents) and their fitness functions, changes over time[7]. In terms of problem structure, innovative design is more an evolving process between design problem and design solution [8]. During the evolution process, the actions of design activities result in the potential experience accumulation or modification of rules.

We synthesize these insights into the basic model ideas as follows: The process of innovative design is a CAS devised to fit varied circumstances, where activities are agents, deliverables imply their connections. The process adaptability of innovative design is determined by the number and structure of design activities, their relationships and the decision ability.

In this model, design activities correspond to agents; design situations correspond to deliverables that connect design activities, as shown in Fig. 1. According to the current design situation, decisions need to be madefor selecting a design activity from design space according to the activity value. The activity value is determined by the state of the design situation and the design activity itself. The design activity with the highest value of activity value, such as the design activity 2 in Fig.1, is chosen. The activity value thus is the basis of selforganization and the emergence of process architecture. The design situation and the design activity also evolve over the course of the innovative design. Eventually, a process architecture emerges from the series of activity selections. In order to construct the process model, it is the key to the modeling design situation, design activity and activity value. We will develop these model components in the following sections.

\subsection{Design Situation}

We perform the evolution of innovative design through a series of state-transitions. The state is defined as the design situation, which denotes the combination of the state of the varied concepts at certain points. Some researchers have modeled the design process through state-transition. For example, the "Signposting" model considers the confidence of parameters as the variety of states [9], while the APDP (adaptive product development process) model encompasses cost, schedule, quality [10]. However, these definitions of state are either more detailed or not complete for innovative design. In order to construct a comprehensive representation of the "design situation", we focus on several elements: product being designed, design context, stakeholders and the state of design process [11], as shown in Fig. 2.

Product being designed refers to a product during the design process because the product itself does not yet exist during this process. A design process can be understood as the mapping of the initial state space of the product into the expected state through a series of transformations (design activity). The FBS model describes the state transformation by the function, behavior and structure of the product being designed [12]. Given a description of the expected functions and behaviors of the product being designed, the designer proposes a structural representation of a product that could produce the functions and satisfy the behaviors. By constantly 
modifying the representation of a product being designed, from one time to the next, the designer finally arrives at the design solution. In other words, at the beginning of the design process, the representation of the product being designed may be formulated in fuzzy and imprecise terms. At some later steps of the design process, this representation will be described in precise details [13]. Therefore, the state-transition of innovative design is the change of product being designed.

Design context is described by the sets of factors influencing the design state and the design process at a certain time. There are three reasons for introducing the design context into the design situation. First, innovative design should provide a means to partition the concepts and the knowledge in order to be more innovative [14]. It is impossible to acquire or generate new knowledge or concepts without the support of the environment. Moreover, the process of innovative design is treated as a system, which evolves by interacting with its environment. Factors of design context, such as organization architecture and organization strategy, influence the process of innovative design. Lastly, the designer is situated in the design context. The designer perceives and interprets design problems differently as the design context changes.

The stakeholder indicates one party with an interest for innovative design. It consists of internal (e.g. project manager, designer, product reviewer and senior manager) and external stakeholders (e.g. customer, user and supplier). The innovativeness of innovative design depends on the stakeholders involved. The stakeholders evaluate the value and the novelty of an innovative solution by communicating with the designer. Some new requirements of stakeholders entail the change of product being designed, even redefinition.

The state of design process is defined as a series of design activities performed by the designer before reaching the current design state. It is useful to know which design activities are not able to have a positive effect in achieving the desired goal and which ones can improve the efficiency of design activities. The designer gains experience from these accomplished design activities, and grounds them on previous knowledge. It can be seen as external information of the designer.

\subsection{Design Activity}

A design activity is a transformation towards the design goal at that moment, carried out by designers, causing the change of the state of the product being designed and the other elements of design situation. Conversely, the four elements of the design situation determine the generation of the potential activity alternatives in design space and partially determine the activity value of these alternatives. Some process models, such as IDEF0, IDEF3, Petri nets, DSM, Signposting and APDP, provide related definitions and representations for design activity or task. Each representation provides a different perspective of process structure and behavior. Each is thus suited to modeling systems with specific characteristics. For example, IDEF0, DSM, Signposting and APDP emphasize information dependence, while IDEF3 and Petri nets assign an important role to information precedence. Here, we adopt the information processing view to represent design activity. Fig. 2 shows the attributes and objects of the design activity.

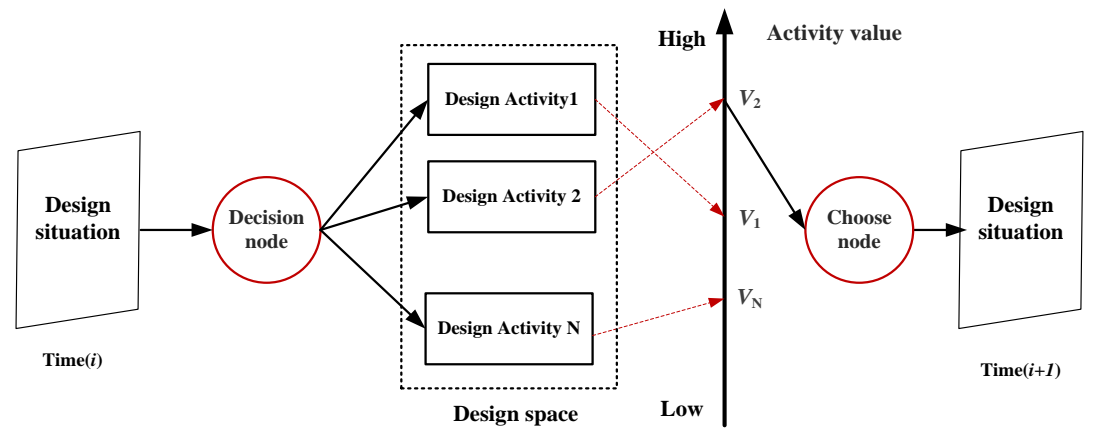

Figure1. THE MODEL FRAMEWORK OF ACTIVITY-NETWORK ADAPTIVE PROCESS MODEL

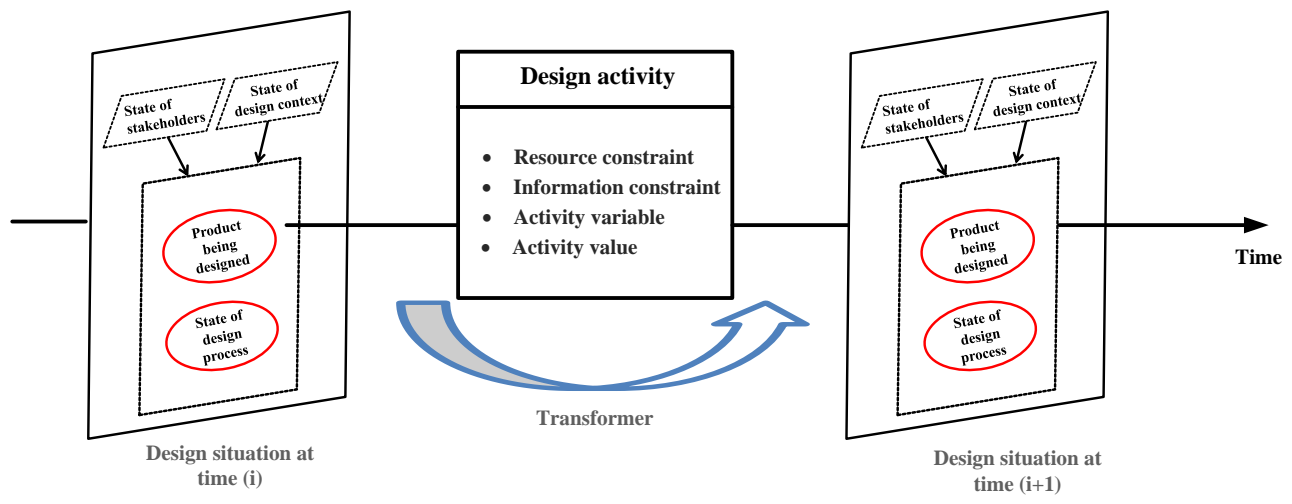

Figure 2. THE MODEL OF DESIGN ACTIVITY AND DESIGN SITUATION 
Design activity is specified by the current design situation which is transformed by design activity to generate the new design situation. Resource constraint and information constraint indicate the condition and resources required for, or constraints upon the design activity's operation; activity variable represents the execution attributes of design activity; activity value is the decision basis of activity selection. We will define them in detail as follows.

Resource constraint and information constraint dictate the resource and information requirement of each design activity. Each constraint indicates the number and variety of resource units and information which the activity requires to operate. Since design activities are commonly interdependent, each requiring the information from other design activities. A design activity cannot be attempted until there is sufficient information. For example, for a test activity, only if all product components have been finished, that is to say, the test activity acquires all necessary product information, can it be performed. Similarly, if there are enough resources in the current situation, the design activity cannot be executed.

Activity variable is the cost and duration of a design activity. We choose the triangle probability distribution to represent the cost and duration of design activity since it is difficult to get these values in real time. For each design activity, it receives three estimates (optimistic, mostly like and pessimistic) for the expected value of durations and costs of one-time execution.

Activity value is a dynamic measurable variable that is determined by the current state of design situation and the design activity itself performed. Within different design situations, the same design activity has different design performances. The evaluation of activity value provides the decision base for choosing the design activity in the adaptive process of innovative design. We will discuss the activity value below in Section 3.

\section{EXPERT EVALUATION TO ADAPT THE MODEL}

This section presents a methodology to elaborate the adaptive design process presented in Section 2 and make it evolve along the project progress with the objective to favor innovation. At given steps of the design (decision nodes in the activities network), the point is to determine, from the current design situation, which activity must take place next from a set of predefined candidate activities.

We propose to rely on expert evaluations to guide this decision. Each candidate activity is assigned an activity value. Roughly speaking, this value represents the probability for the process to reach the design target best if the activity is chosen. This activity value results from joint evaluations of process complexity and product complexity.

On the one hand, to make these analyses precisely, we must use a detailed representation of the design process. We thus decompose the global design process into nine elementary processes. On the other hand, we need to define a set of design metrics. These are related to targets of either the process or the product; they will be helpful to evaluate how far away from these targets the achievement of the process is. Generally speaking, the metrics allow designers to evaluate the balance between innovation degree and control level at a given step of the design process. Section 3.1 introduces the basis of the activity value evaluation and Section 3.2 presents the evaluation method and its various steps.

\subsection{Evaluation Basis}

\subsubsection{Complexity}

From a general perspective, the definition of complexity depends on the concept of "system". It is defined as a quality of an object with many interwoven elements with attributes which make the whole object difficult to understand in a collective sense [15]. Here, innovative design is meant to satisfy the set of specified design targets by a series of design activities. The selection of a design activity determines the probability of achieving these targets. Therefore, following Suh's [16] definition, in our paper complexity is related to information, which is defined as a logarithmic function of the probability of successfully satisfying the design targets.

According to the definition above, the complexity of innovative design decreases over time, as shown in Fig. 3(a). At the beginning of an innovative design $\left(t_{0}\right)$, because of unavailable information and project uncertainty, designers have the greatest probability of not satisfying the project targets. Complexity thus reaches the highest value. With increasing information available, complexity decreases to the lowest value until the end of the design $\left(t_{f}\right)$. Fig. 3(a) indicates the ideal process of innovative design, in which the complexity decreases monotonically over the design time. However, in practice over the course of the design, the change of complexity between time $\left(t_{l}\right)$ and time $\left(t_{l}\right)$ depends on the current state. Fig. 3(b) depicts some alternative profiles of complexity reduction. In designs $\mathrm{B}$ and $\mathrm{C}$, the global composite complexity decreases more steadily, but the change of complexity may increase at some intervals. Therefore, in our paper we link the activity value to the complexity reduction. As shown in Fig. 3(a), during the duration of a design activity (interval $\Delta t$ ), the information created by the design activity causes complexity reduction $(\Delta c)$.

Therefore, calculating the complexity at one interval, first requires the clarification of design targets. When the design targets are defined, their desired target value ranges are specified. However, the actual PDF (probability density function) of the design activity determines the actual possible range, which may be different from the target value, as shown in Fig. 4. In accordance with Suh [16], the overlaping portion represents the probability of successfully satisfying the design targets (the shaded area in Fig. 4).

If the actual possible range for a specified target $\left(T_{i}\right)$ is represented $p_{x}\left(T_{i}\right)$, the probability $P_{i}$ of achieving $T_{i}$ is calculated as the following equation:

$$
P_{i}=\int_{G_{x}^{l}}^{G_{x}{ }^{u}} p_{x}\left(T_{i}\right) d\left(T_{i}\right)
$$


Where, $G_{x}{ }^{l}$ and $G_{x}{ }^{u}$ represent the lower and upper values of the target value range. Hence, the information content $I_{i}$, that helps increase the probability of achieving specified target $\left(T_{i}\right)$ by the design activity follows the equation:

$$
{ }_{i}=\log _{b}\left(P_{i}\right)^{-1}
$$

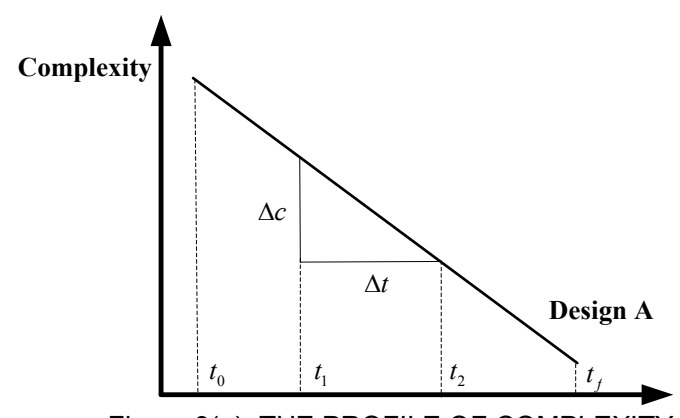

Figure 3(a). THE PROFILE OF COMPLEXITY

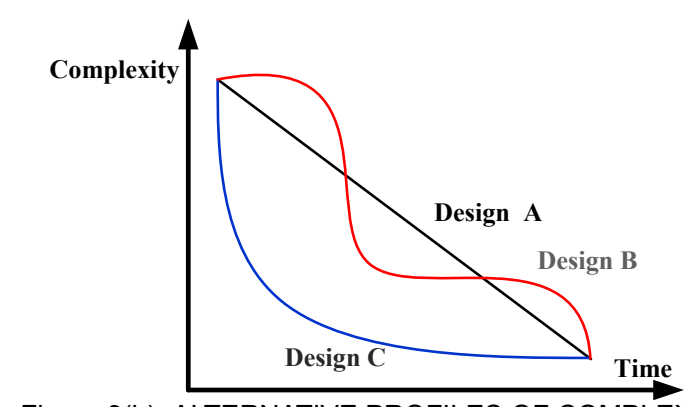

Figure 3(b) .ALTERNATIVE PROFILES OF COMPLEXITY

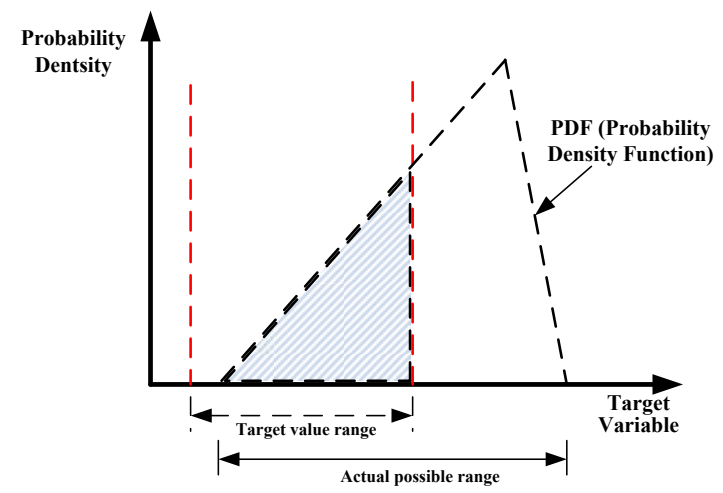

Figure4. THE REPRESENTATION OF THE PROBABILITY OF SUCCESSFULLY SATISFYING DESIGN TARGETS

\subsubsection{Design Metrics}

\section{(1) Classification of design metrics}

Designers use design metrics to track the probability of satisfying the design targets as the design process unfolds. Therefore, before discussing how the activity value is to be evaluated, we should first discuss design metrics to define design targets. In the case of successful products, they should (1) satisfy the customer requirements (2) be sold at the right price (3) reach the market at the right time [19]. The first two prerequisites set design metrics in terms of product, while the last one concentrates the importance of time-to-market, that is, the process management. According to the three prerequisites, we build the design metrics as follows.

In the literature, most researchers focus on design metrics only in terms of technical performance. However, since the uncertainty of requirement in the initial stages of innovative design, it is difficult to clarify the metrics about technical performance. In addition, different design stages need different design metrics to describe targets. It is thus reasonable to set technical performance as design metrics during embodiment design and detail design, while the task clarification and conceptual design focus on the setting of requirements and establishing of functions. Moreover, as the nature of innovative design is different from other design types in terms of task characteristics, the innovative performance is an important design metrics. The right price requires that a company considers the economic aspect of a product (i.e. product cost). Therefore, the design metrics in terms of product should concern innovation performance, function performance, technical performance and product cost.

The right time requires that companies are concerned with improving the efficiency and effectiveness of the design process. In practice, innovation is a coupling and matching process. To validate the effectiveness of an innovative process, there may be substantial iteration or feedback loops from later to earlier design stages. But an excess of iterations raises the process complexity, so there is a need to take time to settle down into stable design configurations. These "emergent properties", such as changes in customer requirements, changes in regulations and environments, would add to the complexity of innovative design [7]. Furthermore, because of today's competitive industrial market, companies are under increasing pressure to create and sustain advantages by reducing design time and cost, while keeping a high design quality. It is thus desirable to set design metrics in terms of process management.

Consequently, we divide design metrics into two classes: product metrics, including innovation performance, function performance, technical performance and product cost; process metrics, which concerns the duration and cost of design project.

\section{(2) Correspondences between design stages and design metrics}

As discussed above, the complexity depends on the targets and the design activity itself. Since different design stages have different targets, the complexity varies at different design stages. After building the design metrics, it is thus necessary to clarify the design metrics of different stages.

Tab.1 shows the corresponding relationship between design stages and design metrics. The notation empty circle $(O)$ denotes dependence of the design stage on the design metric. According to the FBS model [12], design consists of eight elementary steps, which are defined in terms of the key concepts of function, behavior and structure. Five of them transform the desired functions of the product into the design descriptions in sequence. 
Table 1. THE CORRESPONDING RELATIONSHIP BETWEEN DESIGN STAGES AND DESIGN METRICS

\begin{tabular}{|c|c|c|c|c|c|c|c|}
\hline & \multirow{2}{*}{\multicolumn{2}{|c|}{ The nine elementary process of innovative design }} & \multicolumn{4}{|c|}{ Design metrics (Product) } & \multirow{2}{*}{$\begin{array}{l}\text { (Process) } \\
\text { Cost and } \\
\text { duration }\end{array}$} \\
\hline & & & Innovation & Function & $\begin{array}{c}\begin{array}{c}\text { Technical } \\
\text { performance }\end{array} \\
\end{array}$ & Cost & \\
\hline Process 0 & $\mathrm{R} \rightarrow \mathrm{F}$ & $\begin{array}{l}\text { Transformation of customer requirements into functions } \\
\text { expected to contribute to these requirements }\end{array}$ & $\begin{array}{c}\mathrm{O} \\
\text { new function }\end{array}$ & O & & & O \\
\hline Process 1 & $\mathrm{~F} \rightarrow \mathrm{B}_{\mathrm{e}}$ & $\begin{array}{l}\text { Transformation of these functions into behaviours that are } \\
\text { expected to enable the functions }\end{array}$ & $\begin{array}{c}\mathrm{O} \\
\text { new behaviour }\end{array}$ & & & O & O \\
\hline Process 2 & $\mathrm{~B}_{\mathrm{e}} \rightarrow \mathrm{S}$ & $\begin{array}{l}\text { Transformation of the expected behaviours into a solution } \\
\text { structure that is intended to exhibit the desired behaviours. }\end{array}$ & $\begin{array}{c}\mathrm{O} \\
\text { new structure }\end{array}$ & & O & O & O \\
\hline Process 3 & $\mathrm{~S} \rightarrow \mathrm{B}_{\mathrm{s}}$ & $\begin{array}{l}\text { Derivation of the 'actual' behaviours from the synthesized } \\
\text { structures }\end{array}$ & & & & & O \\
\hline Process4 & $\mathrm{B}_{\mathrm{s}} \leftrightarrow \mathrm{B}_{\mathrm{e}}$ & $\begin{array}{l}\text { Comparison the behaviour derived from structure with the } \\
\text { expected behaviour }\end{array}$ & & & & & O \\
\hline Process5 & $\mathrm{S} \rightarrow \mathrm{D}$ & Production of the design description & & & & & O \\
\hline Process6 & $\mathrm{S} \rightarrow \mathrm{S}^{\prime}$ & Choice of a new structure & $\begin{array}{c}\mathrm{O} \\
\text { new structure }\end{array}$ & & O & O & O \\
\hline Process 7 & $\mathrm{~S} \rightarrow \mathrm{B}_{\mathrm{e}}{ }^{\prime}$ & Choice of new expected behaviour & $\begin{array}{c}\mathrm{O} \\
\text { new behaviour }\end{array}$ & & O & O & O \\
\hline Process 8 & $\mathrm{~S} \rightarrow \mathrm{F}^{\prime}$ & Choice of new functions & $\begin{array}{c}\mathrm{O} \\
\text { new function }\end{array}$ & O & O & O & O \\
\hline
\end{tabular}

R: requirement; F: function; $\mathrm{S}$ : structure; $\mathrm{B}$ : behavior; $\mathrm{B}_{\mathrm{e}}$ : expected behaviors; $\mathrm{B}_{\mathrm{s}}$ : behavior derived from structure

Due to the lack of a comprehensive representation of the sources of innovation, the original framework is restricted to the internal process of innovative design. To better and comprehensively exploit this process, we add requirements (R) into the original framework of innovative design [11]. Therefore, the whole process of innovative design is extended to the nine elemental processes, as shown in the left column of Tab. 1. These processes correspond to different design metrics in terms of product and process (as described in a sub-section above), as seen in the first row of Tab.1.

The column "innovation" depicts the design metrics for the degree of creativity. The creative process is an integral part of the innovative design. Three creative process elements (analysis, generation and evaluation) can be mapped onto a view of the design process. Processes $0,1,2,6,7,8$ correspond to the generation stage of the creative process, which results in the generation of new function, new behavior or new structure [11]. Hence, these processes should consider the degree of creativity as one of the design metrics. The column "function" represents the design metrics for product function. Processes 0 , 8 involve the establishment of functions by transformation of requirements or structures. Whether these functions can satisfy the requirements or match the structures is the main target within the two processes. The column "technical performance" refers to the technical attributes of a product and entails a product's conformance to its technical requirement [17]. Since process 0 and 1 are the initial stages of the innovative design, it may only be possible to decide how likely it is that certain requirements can be fulfilled. In that case, to evaluate the likelihood of fulfilling technical performance may not be possible. Additionally, Processes 3, 4 and 5 only focus on analysis activity, not the increase of technical performance. As a result, processes 2, 6, 7 and 8 should consider technical performance. The column "cost" indicates that a product's economic characteristics should be viewed as constraints. A product should be sold at the right price. It is thus required that the economic aspects be taken into consideration, at least qualitatively, over the course of generation of design solutions (i.e. Processes 1,2,6,7 and 8). The column "cost and duration" represents the cost and time that have been spent by far. The expected duration and cost are the primary process metrics and objective functions used by most of the models. In order to avoid overturning the budget and deadline, the cost and duration should be controlled at every process (Processes $0-8$ ).

\subsection{Evaluation Method for Activity Value}

\subsubsection{Evaluation Steps}

In what follows we discuss the basic evaluation steps of the activity value. The first step is to construct the set of the targets for the selected design activity based on Tab. 1. As the basis of evaluation of design activity, it should define the targets and specify the target value ranges. Since different design stages have different focuses, the targets of the design activity should be selected based on the current design situation.

The second step is to evaluate the absolute value of the design activity. This value only refers to the effects of design activity on increasing the probability of achieving these targets, which is independent of the design situation. The overall absolute value is calculated as the following equation:

$$
C_{\text {absolute }}=\sum_{i} w_{i} I_{i}
$$

Where, $w_{i}$ is the weight, and all $w_{i}$ sum to one. Since the activity value depends on the design situation, $w_{i}$ is the 
dynamic factor, which is determined by the current needs to reduce complexity in the particular targets identified. The sum of $i$ denotes the number of the targets $T_{i}$ for the selected design activity. $I_{i}$ represents the information content that increases the probability of satisfying the target $T_{i}$. According to Eqn. (1) and (2), Eqn. (3) can be transformed into the following equation:

$$
C_{\text {absolute }}=\sum_{i} w_{i} \log _{b}\left(\int_{G_{x}{ }^{u}}^{G_{x}{ }^{l}} p_{x}\left(T_{i}\right) d\left(T_{i}\right)\right)^{-1}
$$

As for the representation of uncertainty $\left(p_{i}\right)$, traditional process simulation models have used the PDF (probability density function) to represent activity cost, duration and technical performance. However, concerning the design metrics listed in Tab. 1, because of the different essence, it is difficult to represent uncertainty by PDF, such as "innovation". Hence, as for different design metrics, different representation methods should be adopted. We will discuss this point further in Section 3.2.2.

The last step is to evaluate the actual value of the selected design activity. As defined in Section 3.1.1, the activity value is determined by the reduction of complexity. Thus, the activity value $\left(V_{a}\right)$ is the difference in complexity before and after the activity, which is represented by the following equation:

$$
V_{a}=C_{\text {actual }} \quad C_{\text {absolute }}
$$

Where, $C_{\text {actual }}$ is the information content of complexity before the activity, which is the actual value based on the state of design.

\subsubsection{Two Techniques to Evaluate the Absolute} Value of the Design Activity

In order to evaluate the absolute activity value, it is essential to specify the actual possible range $p_{x}\left(T_{i}\right)$ and target value range for a specified target $\left(T_{i}\right)$ in the light of Eqn. (4) and Fig. 4. In other words, how to evaluate the complexity for each metrics in Tab. 1. As discussed above, because of different difficulty degrees in acquiring information and problem essence, different metrics in Tab. 1 need different evaluation methods. As for innovation performance, it is first very hard to specify concrete numerical value. Moreover, when performing a design activity, unlike technical performance, designers cannot give the possible outcome by the PDF. Consequently we will discuss the evaluation method for innovation performance and other design metrics, respectively.

\section{(1) Evaluation of innovation performance}

The innovation performance reflects the change degree of product being designed by a design activity, that is to say, the degree of creativity. Mensh [18] studies the frequency of innovation with different degrees of creativity, and finds that radical innovation happens 29 times, and important improvement innovation 145 times, while the frequency of minor product or process differentiation with new technology appears 760 times in the period 1953-1973. In other words, the greater the creativity degree, the smaller the frequency. As for innovative design, there is lower probability (or higher uncertainty) for a design activity with a high degree of creativity. More information is needed to get the generation of radical design variable(s).

In information theory, a random variable with greater probability (uncertainty) has greater information. Hence, we consider the valuation of information embedded in the design as the representation structure for the evaluation of innovation performance. Here, we evaluate the information content ( $\left.I_{\text {innovation }}\right)$ of the innovation performance for a design activity by calculating the uncertainty of the change of the state space of the product being designed. Let $X_{1}, X_{2}, \cdots, X_{L}$ be independent, where each $X_{i}$ denotes a new design variable (function, behavior and structure) generated by a design activity, and $L$ is the number of the changed design variables. Furthermore, $P\left(X_{i}\right)$ is the probability for $X_{i}$ occurrence, which reflects the degree of creativity of $X_{i}$. For example, if $X_{i}$ is a new function with the higher degree of novelty, it means that $P\left(X_{i}\right)$ is smaller. According to the information theory, the information for $X_{i}$, as the innovation performance of $X_{i}$, is defined as

$$
I_{\text {innovation }}\left(X_{i}\right)=\log _{b} P\left(X_{i}\right)^{-1}
$$

Since $X_{1}, X_{2}, \ldots, X_{L}$ is independent, the information content of innovation performance for a design activity $I_{\text {innovation }}\left(X_{l}\right.$, $\left.X_{2}, \ldots, X_{L}\right)$ is defined as

$$
\begin{aligned}
& I_{\text {innovation }}\left(X_{1}, X_{2}, \ldots ., X_{L}\right)=I\left(X_{1}\right) I\left(X_{2}\right) \ldots \ldots I\left(X_{L}\right) \\
& =\log _{b}\left(P\left(X_{1}\right) P(X) \ldots \ldots P(X)\right)^{-1}
\end{aligned}
$$

The next question is how to generate the value of $P\left(X_{i}\right)$. Since the degree of creativity is related to $X_{i}$ 's distance from the current design paradigm, $P\left(X_{i}\right)$ depends somehow on the particular design problems. Moreover, different generation ways of $X_{i}$ result in different degrees of creativity. In the absence of further information, we use the estimate to generate $P\left(X_{i}\right)$ by expert evaluation. Designers can use methods such as the Delphi method and the AHP method to estimate the value of $P\left(X_{i}\right)$.

\section{(2) Evaluation of other performances}

As opposed to the innovation performance, the target values of design metrics "function" and "technical performance" can be estimated early in the design process, as soon as the baseline is built. In addition, the function and technical performance become more accurate as the design progresses. In other words, information created by the design activity reduces the complexity of the two metrics over time. For product cost, project cost and duration, the project budget and deadline can also be established at the beginning of the design. Therefore, the ranges of target value for the targets above can be specified. And these ranges can be modified in accordance with the state of the design situation.

Since PDF indicates the possible outcomes and the relative probability (e.g. Fig. 4), a variety of PDFs have been used to represent the uncertainty in process models. In our model, 
because one does not have much information about all possible outcomes for the performances above, we adopt the triangle probability distribution (optimistic value, mostly like value and pessimistic value) to depict the potential outcomes. Hence, according to Eqn. (1) and (2), the function and technical complexity is evaluated as

$$
I_{X}=\log _{b}\left(\int_{G_{x}^{u}}^{G_{x}^{l}} P_{x}(x) d x\right)^{-1}
$$

Where $I_{x}$ represents $I_{\text {function }}$ or $I_{\text {technology }} ; x$ is the outcome; $G_{x}{ }^{l}$ and $G_{x}{ }^{u}$ represent the lower and upper values of target value range; $P_{x}(x)$ is the PDF of the target. Because the product cost, project budget and deadline are single numerical values, their complexity is evaluated as

$$
I_{X}=\log _{b}\left(\int_{-\infty}^{G_{x}} P_{x}(x) d x\right)^{-1}
$$

\section{SIMULATION AND RESULTS}

\subsection{Simulation Framework}

We use a discrete-event simulation to construct the process architecture of innovative design by the adaptive process model. The simulation proceeds with selecting a design activity according to the activity value, within the current available information. Each simulation run begins at the design situation $t(0)$, with a series of design goals (budgets, design duration, product cost) and requirement information.

In each design situation $t(i)$, the simulation first identifies the next available design activities satisfying both precedence and resource constraints for each independent design activity. Because iteration is the fundamental characteristic of the design process, the simulation also supports iterations between design activities. That is, the potential design activities could consist of these previously performed design activities. Then it calculates the activity value $\left(V_{a}\right)$ of each potential design activity according to the calculation method discussed in Section 3. The design activity with the highest value then is selected in each independent design activity, as the next one of the set of design activities. After that, the simulation generates the actual values of process variables and activity variables with a randomly sampled via Monte Carlo technique. The duration of the design situation is defined as the duration of the shortest activity in the set of design activities. Once the shortest design activity ends, the activity duration and cost, as well as the effects of the work done on the set of design activities, are added to the next design situation. If all the remaining design activities are finished or the cumulative time reaches the design duration (the termination condition), one simulation run is complete.

\subsection{Case Description}

We applied the model to simulate an automobile design project that mainly designed a series of new mini-cars. It catered for the young people, especially fashion-conscious people. The overall goal was to design a new mini-car with an appealing look, fashionable configurations, and high quality life at low usage cost. Therefore, it required innovation on style design, structure design and engine design of the car to satisfy the above requirements while paying attention to product cost. Generally, the whole vehicle development process consists of product planning stage, vehicle concept stage and vehicle development stage (see Fig. 5). According to the check points, this process can be decomposed into a series of sub-processes (P0, P1..., and P9). The main design activities are performed in the processes $\mathrm{P} 1 \sim \mathrm{P} 6$, such as concept design and digital engineering design.

The DSM of Fig.6 represents the network of the main design activities. This DSM was built by asking designers and consulting the design documents to depict the information flow between design activities. Based on the DSM, we constructed the design space of each activity that included the potential design activities and possible rework activities. As for the design metrics in Section 3.1.2, the goal of this project was to design a fashionable mini-car with high quality at low usage cost. According to the designer interviewed, for the metrics "innovation", it focused on the "behavior" and "structure" parts; for the metrics "TPM", the engine and appearance parameters were the main characteristics of the end product; for the metrics "product cost", the project set the future sale price range as the design constraints; for the metrics "cost and duration", the design budget and deadline were clarified in Process P0.

\subsection{Simulation Results and Analysis}

After 2500 simulation runs, we gained the most frequent process architecture (109 times), as shown in Fig. 7(b). The black bar indicates the duration of the design activity, while the red one represents the iteration of this design activity. Compared with the current design process architecture in the project (Fig. 7(a)), the most frequent process architecture reduced the iteration of conceptual design activities by sequencing the activities. The result was in accordance with the goal of this project and the adaptive model. Since one of the project goals was to design a new fashionable mini-car, the innovative activities happened during the conceptual design. It thus resulted in the iterations to explore innovative ideas at this stage. Moreover, the activity value, as the decision criterion for balancing the innovation and control, reduced the iterations. At the engineering design stage (i.e. embodiment design), the difference manifests the reduction of duration. Because engineering design is very mature within the car industry and has a standard and rigid operation process, there are not many modifications in design space and the sequences. As for the last two stages, they focused on the verification of the whole car and components. Hence, there was little difference between the two process architectures. 


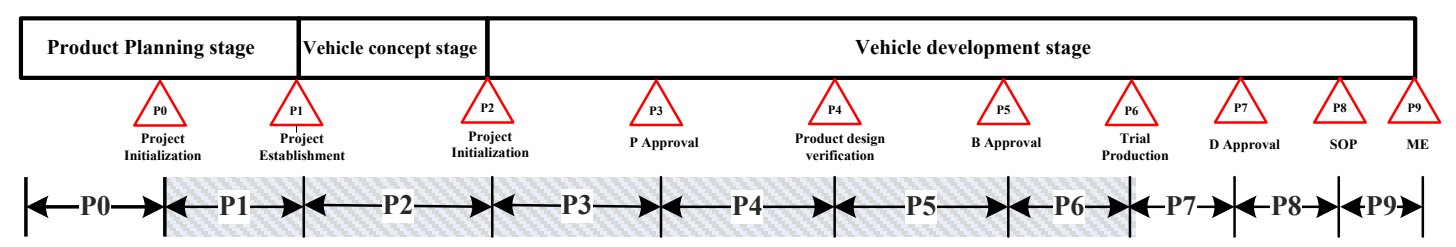

Figure 5 THE WHOLE VEHICLE DEVELOPMENT AND DESIGN PROCESS

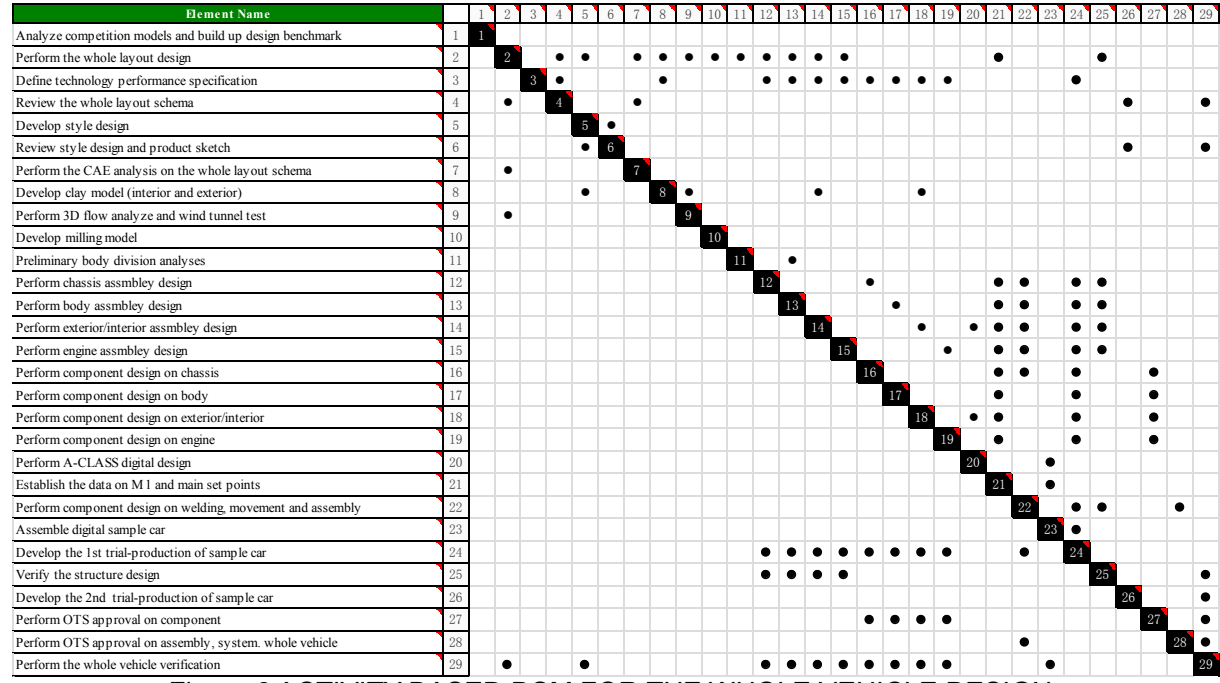

Figure 6 ACTIVITY-BASED DSM FOR THE WHOLE VEHICLE DESIGN

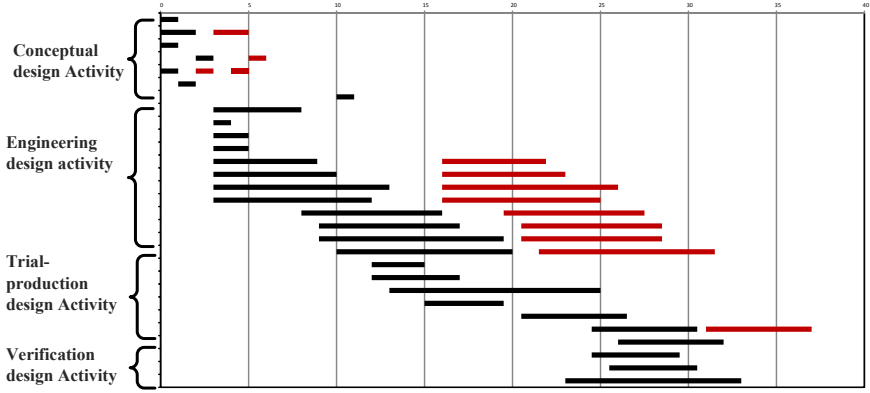

Figure 7(a) THE CURRENT DESIGN PROCESS ARCHITECTURE

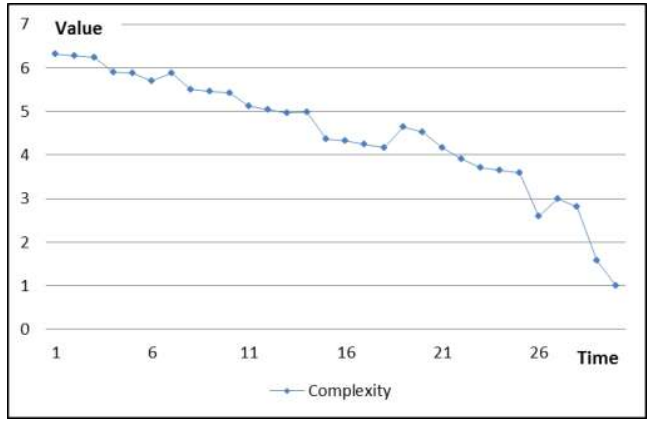

Figure 8(a) THE PROFILE OF COMPLEXITY

Fig. 8 shows the profile of complexity and design metrics for the most frequent design process architecture. In Fig.8 (a), the global complexity decreases more steadily over time, but the change of complexity obviously increases at three intervals (i.e.; time $<6 \sim 8>$; time $<17 \sim 21>$; time $<26 \sim 28>$ ). The three intervals focused on the assembly design, component design

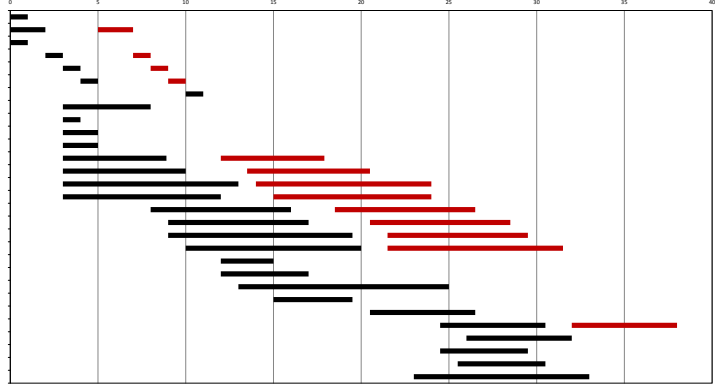

(b) THE MOST FREQUENT DESIGN PROCESS ARCHITECTURE

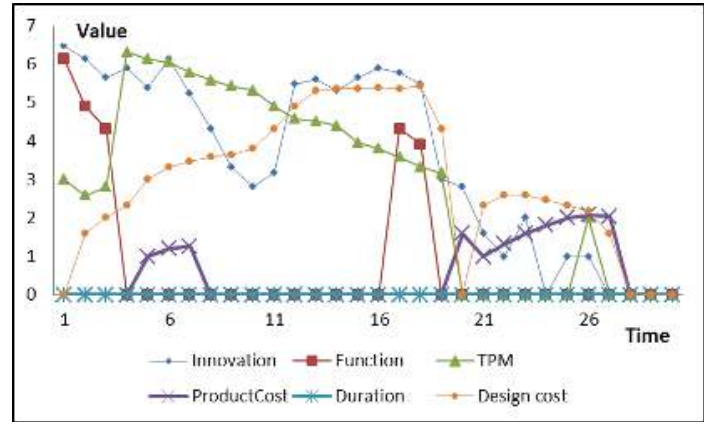

Figure 8(b) THE PROFILE OF DESIGN METRICS

and trial-production, respectively. From the description of Fig.8 (b), design activities involve with the increase of complexity on technology, product cost, design cost and schedule during these intervals. In addition, Fig.8 (b) also depicts the change of innovation performance. At the stage of conceptual design, assembly design and component design, the innovation 
performance is higher than at other stages. As discussed above, since the goal of innovation emphasized the "behavior" and "structure" parts, it resulted in many innovative activities at these stages.

\section{CONCLUSION AND PERSPECTIVES}

In this paper, we proposed an activity-based adaptive process model that viewed innovative design as a complex adaptive system. In contrast to conventional process models that predefine the process architecture, we adaptively select design activity by the activity value in the light of the current design situation. Moreover, the paper contributes a method to evaluate the activity value of innovative design as a function of the information that reduces complexity. The method is based on the comprehensive understanding of design stages of innovative design and their design metrics. The approach integrates the evaluation of innovative performance and other design metrics to balance innovation and control. Finally, through the simulation of this model on a vehicle design process, we validated this model and found several insights. Therefore, this model can provide a support tool for managers and designers to better deal with the design process, in particular innovative design.

Some improvements will still be needed for future research. First, the current constructs of design spaces are mainly based on the designer expertise. But we think the choice of different activities in the design space can also be guided by product or by process architecture. Secondly, the evaluation of innovation performance is calculated by designers based on the comparison with the existing product. Therefore, the construction of knowledge resource on innovation seems worth a further study.

\section{REFERENCES}

[1] Luchs M., and Swan K. S., 2011, "Perspective: The Emergence of Product Design as a Field of Marketing Inquiry*," Journal of Product Innovation Management, 28(3), pp. 327-345.

[2] IEEE Computer Society, 2005, "ISO 15288: Adoption of ISO/IEC 15288:2002 Systems Engineering-System Life Cycle Processes."

[3] Browning T. R., and Ramasesh R. V., 2007, "A Survey of Activity Network-Based Process Models for Managing Product Development Projects," Production and Operations Management, 16(2), pp. 217-240.

[4] Zhang Q., Deniaud I., Caillaud E., and Baron C., 2011, "Process Modeling in Innovative Design using Systems Enginerring," Insight, 14, pp. 31-32.

[5] Holland J. H., 1992, Adaptation In Natural And Artificial Systems, MIT Press, Cambridge, MA.

[6] Engel A., Reich Y., Browning T. R., and Schmidt D. M., 2012, "Optimizing system architecture for adaptability," Proceedings of the 12th International Design Conference DESIGN 2012, pp. 1677-1688.
[7] Anderson P., 1999, "Complexity Theory and Organization Science," Organization Science, 10(3), pp. 216-232.

[8] Dorst K., and Cross N., 2001, "Creativity in the design process: co-evolution of problem-solution," Design Studies, 22(5), pp. 425-437.

[9] Clarkson P. J., and Hamilton J. R., 2000, "'Signposting', A Parameter-driven Task-based Model of the Design Process," Research in Engineering Design, 12(1), pp. 18-38.

[10] Lévárdy V., and Browning T. R., 2009, “An Adaptive Process Model to Support Product Development Project Management," IEEE Transactions on Engineering Management, 56(4), pp. $600-620$.

[11] Zhang Q., Deniaud I., Caillaud E., and Baron C., 2012, "Descriptive model for interpreting innovative design," Proceedings of the 12th International Design Conference DESIGN 2012, Dubrovnik - Croatia, pp. 343-353.

[12] Gero J. S., 1990, "Design prototypes: a knowledge representation schema for design," AI magazine, 11(4), pp. 26-36.

[13] Braha D., and Maimon O., 1998, A Mathematical Theory of Design: Foundations, Algorithms and Applications, Kluwer Academic Publishers.

[14] Hatchuel A., and Weil B., 2009, “C-K design theory: an advanced formulation," Research in Engineering Design, 19(4), pp. 181-192.

[15] El-Haik B., and Yang K., 1999, "The components of complexity in engineering design," IIE Transactions, 31(10), pp. 925-934.

[16] Suh N. P., 2001, Axiomatic Design: Advances and Applications, Oxford University Press, New York.

[17] Browning T. R., Deyst J. J., Eppinger S. D., and Whitney D. E., 2002, "Adding value in product development by creating information and reducing risk," IEEE Transactions on Engineering Management, 49(4), pp. 443 - 458.

[18] Mensch G., 1979, Stalemate in technology: innovations overcome the depression, McGraw-Hill, Cambridge, Ma. 